\title{
Diagnostic accuracy of the Xpert MTB/Rif Ultra for tuberculosis adenitis
}

\author{
Katherine Antel ${ }^{1 *}$ (D), Jenna Oosthuizen ${ }^{1}$, Francois Malherbe ${ }^{2}$, Vernon J. Louw ${ }^{1 \dagger}$, Mark P. Nicol ${ }^{3 \dagger}$, Gary Maartens ${ }^{4}$ and \\ Estelle Verburgh ${ }^{1}$
}

\begin{abstract}
Background: The WHO recently recommended the new Xpert MTB/RIF Ultra assay (Ultra) instead of the Xpert MTB/RIF assay because Ultra has improved sensitivity. We report the diagnostic accuracy of Ultra for tuberculous adenitis in a tuberculosis and HIV endemic setting.

Methods: We obtained fine-needle aspirates (FNA) and lymph node tissue by core-needle biopsy in adult patients with peripheral lymphadenopathy of $>20 \mathrm{~mm}$. Ultra and mycobacterial culture were performed on FNA and tissue specimens, with histological examination of tissue specimens. We assessed the diagnostic accuracy of Ultra against a composite reference standard of 'definite tuberculosis' (microbiological criteria) or 'probable tuberculosis' (histological and clinical criteria).

Results: We prospectively evaluated 99 participants of whom 50 were HIV positive: 21 had 'definite tuberculosis', 15 'probable tuberculosis' and 63 did not have tuberculosis (of whom 38\% had lymphoma and 19\% disseminated malignancy). Using the composite reference standard the Ultra sensitivity on FNA was 70\% (95\% CI 51-85; 21 of $30)$, and on tissue was $67 \%(45-84 ; 16 / 24)$ these were far superior to the detection of acid-fast bacilli on an FNA (26\%; 7/27); AFB on tissue (33\%; 8/24); or tissue culture (39\%; 9/23). The detection of granulomas on histology had high senstivity (83\%) but the lowest specficity. When compared with culture the Ultra on FNA had a sensitvity of 78\% (40-97; 7/9) and tissue 90\% (55-100; 9/10).

Conclusions: Ultra performed on FNA or tissue of a lymph node had good sensitivity and high specificity. Ultra had a higher yield than culture and has the advantage of being a rapid test. Ultra on FNA would be an appropriate initial investigation for lymphadenopathy in tuberculosis endemic areas followed by a core biopsy for histopathology with a repeat Ultra on tissue if granulomas are present.
\end{abstract}

Keywords: Tuberculosis, Xpert MTB/RIF Ultra, HIV, Fine-needle aspiration, Core needle biopsy

\section{Background}

Lymph nodes and pleura are the most common sites of involvement in extrapulmonary tuberculosis (EPTB), which is more common in people living with HIV (PLWH) [1]. EPTB is difficult to diagnose because it is usually paucibacillary and conventional methods for diagnosis, such as microscopy and culture, have low yields, culture results may take several weeks and histological findings (e.g. granulomas) are not specific for tuberculosis. Following a systematic review, the WHO has

\footnotetext{
* Correspondence: katherineantel@gmail.com

†Vernon J. Louw and Mark P. Nicol contributed equally to this work.

${ }^{1}$ Division of Haematology, Department of Medicine, University of Cape Town,

Anzio Rd, Observatory, Cape Town 7925, South Africa

Full list of author information is available at the end of the article
}

recommended that the rapid nucleic acid amplification test Xpert MTB/RIF assay (Xpert) should be used in the diagnosis of EPTB, including lymph node tissue [2]. In this meta-analysis (13 studies, 955 samples), the pooled sensitivity of Xpert on lymph node (tissue or fine needle aspirate (FNA)) was $83.1 \%$ (95\% CI 72-91), and pooled specificity was $94 \%$ (95\% CI 88-97\%). Xpert has been recently superseded by the Xpert MTB/RIF Ultra assay (Ultra), which has greater sensitivity for the detection of Mycobacterium tuberculosis complex in sputum specimens but has lower specificity, especially in patients with previous tuberculosis [3].

The Ultra differs from the earlier Xpert assay in a number of ways: two different multicopy amplification

(c) The Author(s). 2020 Open Access This article is distributed under the terms of the Creative Commons Attribution 4.0 International License (http://creativecommons.org/licenses/by/4.0/), which permits unrestricted use, distribution, and reproduction in any medium, provided you give appropriate credit to the original author(s) and the source, provide a link to the Creative Commons license, and indicate if changes were made. The Creative Commons Public Domain Dedication waiver (http://creativecommons.org/publicdomain/zero/1.0/) applies to the data made available in this article, unless otherwise stated. 
targets (IS6110 and IS1081) have been added to improve detection of $M$. tuberculosis and melting temperaturebased polymerase chain reaction (PCR) analysis (melting curve analysis) is used to improve the detection of rifampicin resistance [4]. Because the limit of detection of Ultra is lower (15.6 bacterial colony-forming units (CFU) per ml compared with $114 \mathrm{CFU}$ per ml with Xpert), the greatest improvement in detection is likely to be in paucibacillary samples. This has been demonstrated in cerebrospinal fluid, where Ultra has much higher sensitivity (95, 95\% CI 77-99), versus Xpert at $45 \%$,) with only a marginally reduced specificity ( $95.6 \%$ vs $98.3 \%$ ) which was thought to be due to antecedent tuberculosis infection [5]. The performance on Ultra in lymph nodes has only been tested in one small retrospective study on 10 frozen samples where it showed an improvement of 50\% compared with Xpert, (5/10 samples that were Xpert negative and culture positive were positive on Ultra) [6].

In this study, we determined the diagnostic accuracy of Ultra for the detection of $M$. tuberculosis in specimens of lymph node obtained by FNA and core-needle biopsy.

\section{Methods}

\section{Study design and participants}

We conducted a prospective diagnostic accuracy study of Ultra on both FNA and lymph node core-needle biopsy tissue in patients with suspected tuberculosis adenitis. The study was performed at Groote Schuur Hospital, a tertiary referral academic centre in Cape Town, South Africa. Eligible study participants were adults ( $\geq 18$ years), both inand outpatients, referred with enlarged lymph nodes of $>20 \mathrm{~mm}$ in the widest diameter located in either the cervical, axillary or inguinal region. Patients on tuberculosis therapy were enrolled provided this had been given for $<1$ month (sub-analyses were done in patients on tuberculosis therapy for $<24 \mathrm{~h}$ ). Patients with contraindications to coreneedle biopsy (low platelets, other coagulopathy and bleeding risk, clinically unstable, site of biopsy unsafe) were excluded. Written informed consent was obtained from all participants. The Human Research Ethics Committee of the Faculty of Health Sciences, University of Cape Town, approved the study.

Patients came from within Groote Schuur and from secondary level hospitals and day clinics in the referral area. Results of prior tuberculosis investigations (sputum Xpert or tuberculosis culture from any site within 3 months of referral, or urine lipoarabinomannan (LAM)) were recorded. Details of HIV status, tuberculosis treatment and ART were obtained.

\section{Data collection}

Demographic information, symptoms, symptom duration, HIV test result, and other TB investigations performed were recorded at enrolment. Performance status was graded according to the Eastern European Cooperative Group (ECOG) [7]. The site of biopsy was recorded, along with other sites of lymphadenopathy. The presence and duration of constitutional symptoms (cough, loss of weight night sweats) were specifically enquired about as was the duration that the patient had noted the lymphadenopathy. Blood was taken for a full blood count with differential, lactate dehydrogenase and HIV status and, if positive, a CD4 count and a viral load for those on ART.

\section{Study procedures and specimen collection}

FNA was performed using a $22 \mathrm{G}$ needle and $5 \mathrm{~mL}$ syringe; further study procedures were determined by the volume of the aspirate sample obtained as shown in Fig. 1. A coreneedle biopsy was only performed when $<0.5 \mathrm{~mL}$ of caseous material was obtained by the aspirate, due to the risk of causing a draining sinus. Initially, when both an FNA and a biopsy were performed on a participant the Ultra was performed only on the tissue, but there was a protocol change after 25 patients and Ultra was performed on both the FNA and tissue on the same patient. When a patient had both an FNA and a core-needle biopsy the TB culture was only performed on the tissue specimen. For the Ultra on the FNA, the needle and syringe were flushed into a sterile container containing $2 \mathrm{~mL}$ of saline. An air-dried

\begin{tabular}{|c|c|c|c|}
\hline & $\begin{array}{l}<0.5 \mathrm{~mL} \text { of } \\
\text { caseous } \\
\text { material }\end{array}$ & $\begin{array}{l}\text { Aspirate specimen } \\
\text { 1. Smear microscopy for AFBs } \\
\text { 2. Ultra } \\
\text { 3. }\end{array}$ & $\begin{array}{l}\text { Tissue specimen } \\
\text { 1. Histology } \\
\text { 2. Ultra }\end{array}$ \\
\hline \multirow{2}{*}{$\begin{array}{l}\text { FNA (22G needle } \\
\text { and } 5 \mathrm{ml} \text { syringe) }\end{array}$} & & & \\
\hline & $\begin{array}{l}\geq 0.5 \mathrm{~mL} \text { of } \\
\text { caseous } \\
\text { material }\end{array}$ & $\begin{array}{l}\text { Aspirate specimen } \\
\text { 1. Smear microscopy for AFBs } \\
\text { 2. Ultra } \\
\text { 3. Mycobacterial culture }\end{array}$ & \\
\hline
\end{tabular}


smear for AFBs was made at the bedside from a second FNA. For culture from the FNA, the aspirate was flushed directed into mycobacterium culture medium (Middlebrook $7 \mathrm{H} 9$ broth medium). The core-needle biopsy was performed by an automated biopsy gun (BARD Magnum $^{\text {tw }}$, CR Bard Inc., Covington, GA, USA) with a 14G needle. If the lymph node was not obviously palpable the biopsy was performed under ultrasound guidance. Two or three cores were sent in formalin for histology (10-15 mm long), an additional core was cut in two with a sterile blade and sent for culture and Ultra, both in $2 \mathrm{ml}$ of $0.9 \%$ saline. If all of the tests performed were inconclusive, the patient underwent a repeat core-needle biopsy or an excision biopsy at the discretion of the treating clinician.

\section{Laboratory tests}

FNA and tissue specimens were transported within $2 \mathrm{~h}$ of collection to a centralized laboratory and processed individually using standardised protocols by trained laboratory staff. The smear slide made at the bedside was examined by Ziehl-Neelsen ( $\mathrm{ZN})$ for AFBs. The tissue obtained by core-needle biopsy was crushed using pestle and mortar. A small portion was smeared on a slide and examined with a ZN stain for AFBs. Mycobacterial culture was performed using an automated liquid mycobacterial culture system (BACTEC ${ }^{\mathrm{mi}}$ MGIT $^{\mathrm{Tm}}$ 960; Becton, Dickinson and Company, New Jersey, USA). Lymph nodes are considered a sterile site and decontamination was not performed prior to liquid biopsy. If the MGIT flagged positive, one droplet was inoculated on $2 \%$ blood agar and incubated for $24 \mathrm{~h}$ to check for bacterial growth. If there was no bacterial growth, the MGIT was reported as positive for mycobacterium, the specimen was decontaminated with sodium hydroxide (1\%) and $\mathrm{N}$-acety-L-cysteine and then repeat MGIT was performed. Positive isolates from culture media were identified by acid-fast staining followed by MRTBDRplus testing (Hain LifeScience, Hehren, Germany) to confirm the presence of $M$. tuberculosis and rifampicin and isoniazid sensitivity.

For the Ultra, $1.4 \mathrm{~mL}$ of specimen reagent was added to $0.7 \mathrm{~mL}$ of aspirate or crushed tissue sample. Results were reported as: invalid (no internal assay control detected); not detected; or detected (with semi-quantitation: trace, very low, low, medium, or high) and rifampicin resistance (detected, not detected, or indeterminate). Staff performing Ultra were blinded to clinical and other microbiological results.

Histological review was performed by a qualified anatomical pathologist who was blinded to the results of the ULTRA and did not have access to the culture, but would have been able to see the results of AFBs on microscopy. If granulomas were identified, a separate $\mathrm{ZN}$ stain was performed by the pathologist and a
Periodic acid-Schiff (PAS) stains were performed for fungi.

\section{Case definitions and statistical analysis}

We assigned participants to one of three diagnostic categories on the basis of clinical, histological and microbiological investigations. Definite tuberculosis (culture-positive on FNA/ tissue for $M$. tuberculosis OR AFBs identified on FNA/tissue) Probable tuberculosis (no other diagnosis that would account for lymphadenopathy with one or more of: macroscopic caseation on FNA/tissue OR tuberculosis confirmed microbiologically [Ultra or culture] at a site other than the lymph node (eg pulmonary) OR granulomas on FNA/tissue). The third category was not tuberculosis (did not fulfil the criteria for the other two categories). The Ultra diagnostic accuracy was also reported separately using positive culture only as the reference standard.

Sample size estimation in diagnostic accuracy studies depends on the prevalence of disease [8]. We were expecting a high prevalence of tuberculosis based on a pilot study we conducted of core-needle biopsy in HIV-positive patients, 92\% of whom had tuberculosis lymphadenitis [9], but the proportion of patients with tuberculosis in our study was lower than expected (40\%) in a pilot phase of our study. We estimated the sensitivity and specificity of Ultra would both be around $90 \%$ based on the Cochrane meta-analysis [9]. With a $40 \%$ prevalence of tuberculosis a sample size of 87 is needed for $95 \%$ CI widths of $10 \%$ and with sensitivity and specificity of $90 \%$ [8]. We inflated the sample size to 100 because of uncertainties about the diagnostic accuracy of Ultra.

We calculated sensitivity, specificity, negative predictive value (NPV), positive predictive value (PPV) and likelihood rations by defining true or false positives and true or false negatives against the composite reference standard of probable or definite tuberculosis for our primary analysis. As secondary analyses we also determined the accuracy of Ultra using mycobacterial culture alone as the reference standard. Data was entered into a REDCap ${ }^{\circ}$ database and analysed using the STATAv14 software package (StataCorp, College Station, Texas, USA). Baseline clinical characteristics were compared using the chi-squared or Fisher's exact test for categorical variables and the Kruskal-Wallis test for continuous variables. We counted invalid tests (i.e. Ultra-error) as negative results. This study is reported in accordance with the Standards for Reporting of Diagnostic Accuracy Studies Guidelines [10].

\section{Role of the funding source}

The funders had no role in study design, data collection, data analysis, data interpretation, or writing of the report. The corresponding author had full access to all the 
data in the study and had final responsibility for the decision to submit for publication.

\section{Results}

\section{Demographic and clinical characteristics}

Between November 2017 and October 2018, 154 consecutive patients were evaluated for suspected lymphadenopathy and we enrolled 99 participants for the study (Fig. 2). Ultra of both FNA and core-needle biopsy were performed in 56 participants, 25 participants had Ultra testing of a core-needle biopsy only (prior to protocol change), and 18 had Ultra testing of an FNA only. The majority of participants (84\%) were seen as outpatients. Of the $51 \%(n=50)$ participants who were HIV positive, $62 \%$ $(n=31)$ were on ART and had a median CD4 count of 216 cells $/ \mathrm{mm}^{3}$ (IQR 82-361) and in the participants on ART, 42\% (13/31) were virally suppressed with a viral load lower than the detectable limit $(<20$ RNA copies $/ \mathrm{mL})$. The final diagnosis was definite tuberculosis in 21 (21\%), probable tuberculosis in $15(15 \%)$ and not tuberculosis in 63 (64\%. Table 1 shows baseline characteristics of the participants by diagnostic group.

The median age was significantly higher in the not tuberculosis group. The groups had similar HIV prevalence and, in those who were HIV positive, similar median CD4 counts. Previous tuberculosis, HIV prevalence and CD4 count was similar in all diagnostic outcome groups. Participants in all groups frequently reported cough, night sweats and weight loss. There was also no significant difference in the clinical examination findings of the lymph node. Lymphocyte count, LDH and total white cell count (WCC) were similar, however, anaemia was more common in the participants with definite tuberculosis (present in 81\%) compared with the other two groups $(p=0.041)$.

A high proportion of participants had tuberculosis investigations prior to referral and the frequency of positive results were: sputum Xpert 3/22, urinary LAM 1/5, and tuberculosis culture (5/15) (by site: urine $0 / 1$, blood $1 / 2$, sputum $4 / 12$, lymph node $0 / 1$ (tissue)). Chest $x$-ray had been performed in 36\% and reported as 'suggestive of tuberculosis' by the referring clinician in $28 \%$ of these.

In the not tuberculosis group the final diagnosis was: lymphoma in 24 (38\%), other malignancy in 19 (30\%), reactive lymphadenopathy in 8 (13\%), and miscellaneous other causes (enlarged submandibular salivary gland $(n=4)$, bacterial adenitis $(n=4)$, sarcoidosis $(n=2)$, sinus histiocytosis $(n=1)$, branchial cleft cyst $(n=1))$. The diagnosis of 'bacterial adenitis' was based on $>0.5$ $\mathrm{mL}$ caseous material with lymphadenopathy resolving after drainage and antibiotics, and culture of the caseous material not positive for tuberculosis. In the two cases of sarcoidosis, granulomas were identified on histopathology and chest computed tomography was compatible with sarcoidosis, both participants went on to have a lymph node excision biopsy which was negative on culture for tuberculosis.

Results of investigations and the performance of the Ultra Participants underwent a number of different investigations for tuberculosis and histological examination on the lymph node; Fig. 2 shows the participant test results by diagnostic outcome groups. The diagnostic accuracy of the reference tests (i.e. identification of AFBs, culture

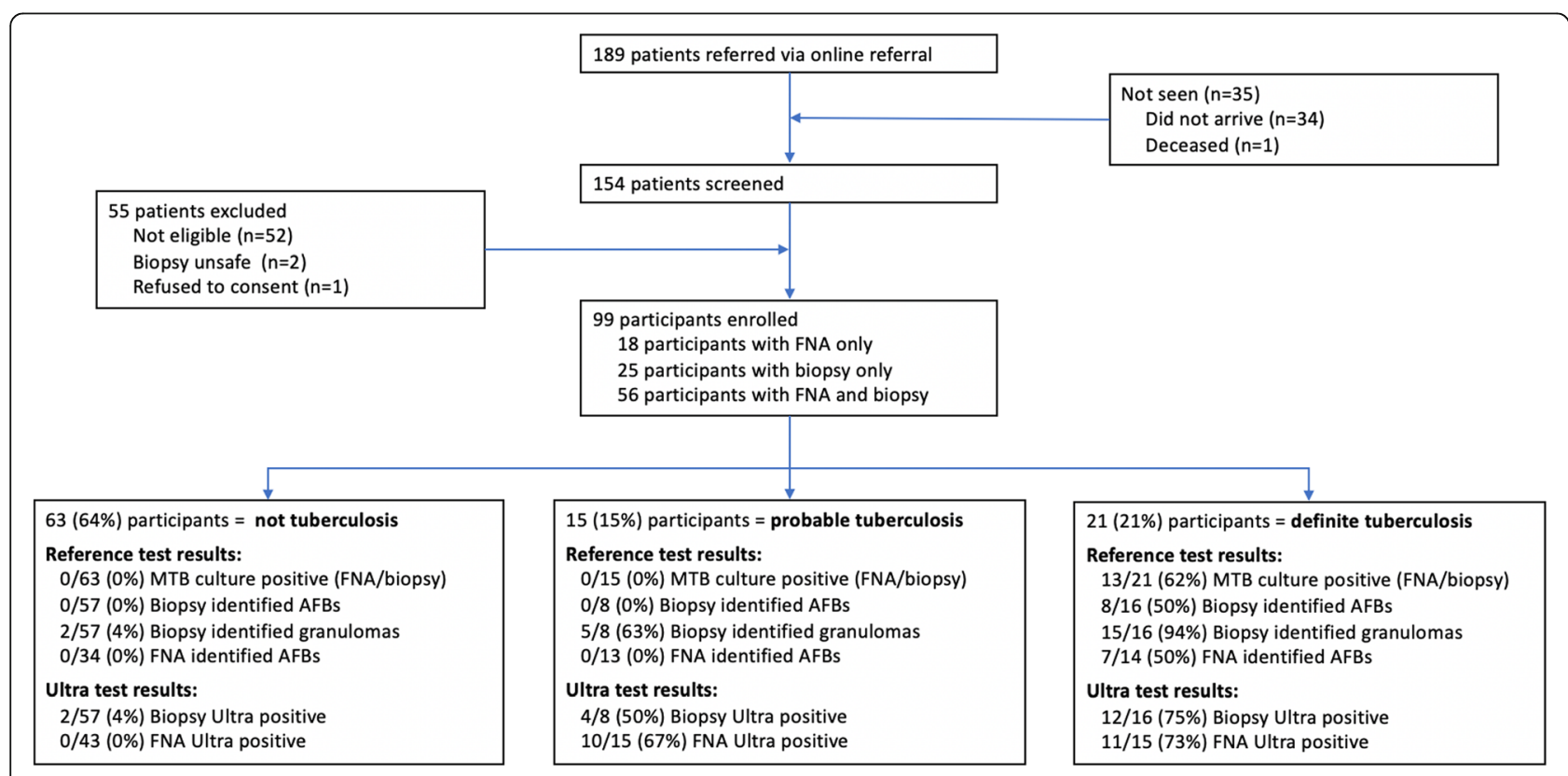

Fig. 2 Trial profile. MTB = Mycobacterium tuberculosis. AFB = acid fast bacilli. FNA = fine-needle aspirate 
Table 1 Baseline characteristics by diagnostic group

\begin{tabular}{|c|c|c|c|c|c|}
\hline & Total $(n=99)$ & Definite TB $(n=21)$ & Probable TB $(n=15)$ & Not TB $(n=63)$ & $P$-value \\
\hline \multicolumn{6}{|l|}{ Sex } \\
\hline Males & $45(45 \%)$ & $9(43 \%)$ & $4(27 \%)$ & $32(51 \%)$ & \multirow[t]{2}{*}{0.233} \\
\hline Females & $54(55 \%)$ & $12(57 \%)$ & $11(73 \%)$ & $31(49 \%)$ & \\
\hline Age (median [IQR]) & $37(30-49)$ & $32(28-35)$ & $36(31-41)$ & $44(32-57)$ & 0.003 \\
\hline \multicolumn{6}{|l|}{ HIV status } \\
\hline Positive & $50(51 \%)$ & $13(62 \%)$ & $8(53 \%)$ & $29(46 \%)$ & \multirow[t]{2}{*}{0.442} \\
\hline Negative & 49 (49\%) & $8(38 \%)$ & $7(47 \%)$ & $34(54 \%)$ & \\
\hline On ARVS & $31(62 \%)$ & $8(62 \%)$ & $7(88 \%)$ & $16(55 \%)$ & 0.263 \\
\hline CD4 count (cells $/ \mathrm{mm}^{3}$, median [IQR]) & $216(82-361)$ & $100(55-254)$ & $351(88-497)$ & $252(92-361)$ & 0.106 \\
\hline$<100$ & $16(32 \%)$ & $6(46 \%)$ & $2(25 \%)$ & $8(28 \%)$ & 0.675 \\
\hline $100-249$ & $10(20 \%)$ & $3(23 \%)$ & $1(13 \%)$ & $6(21 \%)$ & \\
\hline$\geq 250$ & $24(48 \%)$ & $4(31 \%)$ & $5(63 \%)$ & $15(52 \%)$ & \\
\hline \multicolumn{6}{|l|}{ Performance Score } \\
\hline ECOG 0 & 49 (50\%) & $10(48 \%)$ & $9(60 \%)$ & $30(48 \%)$ & \multirow[t]{5}{*}{0.979} \\
\hline ECOG 1 & $28(28 \%)$ & $6(29 \%)$ & $5(33 \%)$ & $17(27 \%)$ & \\
\hline ECOG 2 & $4(4 \%)$ & $1(5 \%)$ & 0 & $3(5 \%)$ & \\
\hline ECOG 3 & $16(16 \%)$ & $4(19 \%)$ & $1(7 \%)$ & $11(17 \%)$ & \\
\hline ECOG 4 & $2(2 \%)$ & 0 & 0 & $2(3 \%)$ & \\
\hline \multicolumn{6}{|l|}{ Patient Type } \\
\hline Inpatient & $16(16 \%)$ & $4(19 \%)$ & $2(13 \%)$ & $10(16 \%)$ & \multirow[t]{2}{*}{0.924} \\
\hline Outpatient & $83(84 \%)$ & $17(81 \%)$ & $13(87 \%)$ & $53(84 \%)$ & \\
\hline Previous tuberculosis & $24(24 \%)$ & $6(29 \%)$ & $6(40 \%)$ & $12(19 \%)$ & 0.205 \\
\hline On tuberculosis treatment & $21(21 \%)$ & $6(29 \%)$ & $6(40 \%)$ & $9(15 \%)$ & 0.059 \\
\hline \multicolumn{6}{|l|}{ Consistency of lymph node } \\
\hline Firm & $81(87 \%)$ & $16(80 \%)$ & $12(86 \%)$ & $53(90 \%)$ & \multirow[t]{2}{*}{0.491} \\
\hline Fluctuant & $12(13 \%)$ & $4(20 \%)$ & $2(14 \%)$ & $6(10 \%)$ & \\
\hline \multicolumn{6}{|l|}{ Symptoms } \\
\hline Cough & $27(27 \%)$ & $6(29 \%)$ & $3(20 \%)$ & $18(29 \%)$ & 0.79 \\
\hline Weight loss & $47(47 \%)$ & $13(62 \%)$ & $5(33 \%)$ & $29(46 \%)$ & 0.222 \\
\hline Night sweats & $29(29 \%)$ & $8(38 \%)$ & $3(20 \%)$ & $18(29 \%)$ & 0.49 \\
\hline \multicolumn{6}{|l|}{ Location of lymph nodes } \\
\hline Unilateral & $61(62 \%)$ & $13(62 \%)$ & $12(80 \%)$ & $36(57 \%)$ & \multirow[t]{2}{*}{0.262} \\
\hline Bilateral & $38(38 \%)$ & $8(38 \%)$ & $3(20 \%)$ & $27(43 \%)$ & \\
\hline \multicolumn{6}{|l|}{ Lymph node FNA/biopsy site } \\
\hline Neck & $85(86 \%)$ & $19(90 \%)$ & $14(93 \%)$ & $52(83 \%)$ & \multirow[t]{3}{*}{0.881} \\
\hline Axilla & $10(10 \%)$ & $2(10 \%)$ & $1(7 \%)$ & $7(11 \%)$ & \\
\hline Inguinal & $4(4 \%)$ & 0 & 0 & $4(6 \%)$ & \\
\hline \multicolumn{6}{|l|}{ Blood results (median [IQR]) } \\
\hline LDH (units/L) & $267(218-341)$ & $292(251-341)$ & $218(194-239)$ & $273(230-366)$ & 0.006 \\
\hline $\mathrm{Hb}(\mathrm{g} / \mathrm{dL})$ & $12.1(9.4-13.4)$ & $10.5(8.7-12.1)$ & $11.8(9.6-12.7)$ & $12.4(9.7-13.5)$ & 0.041 \\
\hline WCC (cells × 10^9) & $6.9(4.9-9.1)$ & $5.3(4.0-8.0)$ & $5.7(4.8-7.3)$ & $7.4(5.2-9.9)$ & 0.142 \\
\hline Lymphocytes (cells × 10^9) & $1.7(1.0-2.4)$ & $1.2(0.7-1.9)$ & $1.7(1.4-2.0)$ & $1.7(1.0-2.7)$ & 0.197 \\
\hline
\end{tabular}

$P$ values $<0.05$ are shown in bold. Data are n/N; \% (95\% Cl). ECOG Eastern Cooperative Oncology Group, LDH Lactate Dehydrogenase, Hb Haemoglobin, WCC White Cell Count 
of lymph node tissue or aspirate) and against the composite reference standard and against culture (of lymph node tissue or FNA) are shown in Table 2. The diagnostic accuracy of Ultra on both FNA and tissue is presented in Table 3 using the composite reference standard, two sub-analyses are presented: the exclusion of participants on tuberculosis therapy, and by using culture (tissue/FNA) alone as the reference test.

There were 55 participants who had an FNA and tissue Ultra and histopathological examination of the lymph node. The result concordance is shown in the Venn diagram (Fig. 3). Of the 6 specimens that showed result discordance between FNA (negative) and tissue (positive), all were 'trace positive' on the quantitative result and 2 of these 6 were considered 'false positives'. These two 'false positive' results both had a histologically proven diagnosis of cancer and one of the two had previous tuberculosis 12 years prior (neither were on tuberculosis treatment at the time of biopsy). Although a dual diagnosis of tuberculosis and cancer is possible, histological examination had no features of tuberculosis in these two cases and was considered unlikely. Of the 5 with necrotising granulomas and with a negative Ultra on both FNA and culture, 2 had definite tuberculosis (1 culture positive, 1 AFB positive), 1 had probable tuberculosis and 2 had sarcoidosis.

There were 4 failed tests (invalid) in the tissue group, and none in the FNA group. There were 12 'trace positive' results, all in the tissue group and 2 of the 12 were considered to be false positive as discussed under discordant results. Rifampicin resistance was identified in 2 of the 39 Ultra positive participants, which was confirmed on line-probe assay.

\section{Discussion}

Our prospective diagnostic accuracy study showed Ultra sensitivity on FNA was 70\% (95\% CI 51-85; 21 of 30), and on tissue $67 \%$ (45-84; 16/24); these were far superior to the detection of acid-fast bacilli on an FNA (26\% [11-46; $7 /$ $27])$, AFB on tissue (33\% [16-55; 8/24], FNA culture [33\% $(10-65 ; 4 / 12])$ or tissue culture $(39 \%$ [20-61; 9/23]). The detection of granulomas on histology had high sensitivity $(83 \%[63-95 ; 20 / 24])$ but had the lowest specificity of all the tests (83\% against culture). Our findings support the use of Ultra on FNA as an initial test when tuberculosis adenitis is suspected as Ultra has a high sensitivity, it is minimally invasive, requires no specialised equipment, and gives a rapid result. Where the FNA does not yield a positive result, core-needle biopsy with histopathology and a repeat Ultra on tissue if there are granulomas, would be cost-effective and yield a high diagnostic rate both for tuberculosis and other conditions (notably malignancy).

We had high precision for Ultra specificity, which is a key parameter given that specificity of Ultra was lower than Xpert in sputum [3]. The sensitivity of Ultra on FNA was $67 \%$ in our study, which is lower than the $87.6 \%$ reported in the Cochrane review [11], but they found sensitivity was lower in adults and with lower prevalence of tuberculosis.

The lower sensitivity of AFB detection and culture on FNA and tissue was poor in our study and is consistent with other studies [12-17]. From our data, the air-dried smear for AFBs from the aspirate can be replaced by the Ultra. Culture is limited both by low sensitivity on the lymph node as well as a long turn-around-time, but it still plays an important confirmatory role in diagnosis particularly where drug resistance is suspected.

There is uncertainty surrounding the interpretation of trace positivity of the Ultra from respiratory samples [3]. In our study, we only had 'trace positive' results on the tissue (12) with none on the aspirate. Of the 6 discordant FNA and tissue results, all were negative on aspirate and trace positive on tissue and two of these 6 were false positives. We suggest that trace positive Ultra results from lymph node tissue or FNA be regarded as positive, but that this result is interpreted together with clinical and histopathological findings. Where the histopathological findings do not show necrotizing granulomas; an excision biopsy would be preferred as this scenario is most likely to represent a false positive result.

Our study has several limitations. First, without a perfect reference standard we needed to define a reference standard; we tried to address this by clearly defining 'definite' and 'probable' tuberculosis. The most stringent definition for a true positive would be culture positivity. We felt it was

Table 2 Sensitivity and specificity of each diagnostic test using the composite reference standard and culture of either lymph node tissue or FNA

\begin{tabular}{lllll}
\hline Tuberculosis test & $\begin{array}{l}\text { Sensitivity against composite } \\
\text { reference }\end{array}$ & $\begin{array}{l}\text { Specificity against composite } \\
\text { reference }\end{array}$ & $\begin{array}{l}\text { Sensitivity against } \\
\text { culture }\end{array}$ & $\begin{array}{l}\text { Specificity against } \\
\text { culture }\end{array}$ \\
\hline AFBs on FNA $(n=61)$ & $7 / 27 ; 26 \%(11-46)$ & $34 / 34 ; 100 \%(90-100)$ & $3 / 8 ; 38 \%(9-76)$ & $49 / 53 ; 92 \%(82-98)$ \\
FNA culture $(n=17)$ & $4 / 12 ; 33 \%(10-65)$ & $5 / 5 ; 100 \%(48-100)$ & $4 / 4 ; 100 \%(40-100)$ & $13 / 13 ; 100 \%(75-100)$ \\
AFBs on tissue $(n=81)$ & $8 / 24 ; 33 \%(16-55)$ & $57 / 57 ; 100 \%(94-100)$ & $4 / 10 ; 40 \%(12-74)$ & $67 / 71 ; 94 \%(86-98)$ \\
Tissue culture $(n=75)$ & $9 / 23 ; 39 \%(20-61)$ & $52 / 52 ; 100 \%(93-100)$ & $9 / 10 ; 90 \%(55-100)$ & $65 / 65 ; 100 \%(94-100)$ \\
$\begin{array}{l}\text { Necrotising granulomas on histology } \\
(n=81)\end{array}$ & $20 / 24 ; 83 \%(63-95)$ & $55 / 57 ; 96 \%(88-100)$ & $10 / 10 ; 100 \%(69-$ & $59 / 71 ; 83 \%(72-91)$ \\
\hline
\end{tabular}

Data are $\mathrm{n} / \mathrm{N} ; \%$ (95\% Cl). FNA Fine-needle aspirate, AFBs Acid fast bacilli, PPV Positive predictive value, NPV Negative predictive value 
Table 3 Diagnostic accuracy of Ultra on FNA and tissue measured against the composite reference standard and culture

\begin{tabular}{|c|c|c|c|c|c|c|}
\hline & Sensitivity & Specificity & PPV & NPV & LR+ & LR- \\
\hline \multicolumn{7}{|l|}{ Composite reference standard } \\
\hline Ultra on FNA ( $n=73$ participants) & $21 / 30 ; 70 \%(51-85)$ & $43 / 43 ; 100 \%(92-100)$ & $100 \%$ & $83 \%$ & inv & 0.3 \\
\hline Ultra on tissue ( $n=81$ participants) & $16 / 24 ; 67 \%(45-84)$ & $55 / 57 ; 96 \%(88-99)$ & $89 \%$ & $87 \%$ & 16.8 & 0.3 \\
\hline \multicolumn{7}{|c|}{ Excluding the 21 participants on tuberculosis therapy $>24 \mathrm{~h}$} \\
\hline Ultra on FNA ( $n=57$ participants) & $12 / 20 ; 60 \%(36-81)$ & $37 / 37 ; 100 \%(91-100)$ & $100 \%$ & $82 \%$ & inv & 0.4 \\
\hline Ultra on tissue ( $n=66$ participants) & $10 / 18 ; 56 \%(31-78)$ & 46/48; 96\% (86-99) & $83 \%$ & $85 \%$ & 14 & 0.5 \\
\hline \multicolumn{7}{|c|}{ Culture as the reference standard ( $n=99$ participants) } \\
\hline Ultra on FNA ( $n=73$ participants) & $7 / 9 ; 78 \%(40-97)$ & $50 / 64 ; 78 \%(66-87)$ & $33 \%$ & $96 \%$ & 3.5 & 0.3 \\
\hline Ultra on tissue ( $n=81$ participants) & 9/10; 90\% (55-100) & $62 / 71 ; 87 \%(77-94)$ & $50 \%$ & $98 \%$ & 6.9 & 0.1 \\
\hline
\end{tabular}

Data are $\mathrm{n} / \mathrm{N} ; \%$ (95\% Cl). FNA Fine-needle aspirate, AFBs Acid fast bacilli, PPV Positive predictive value, NPV Negative predictive value, LR likelihood ratio

justifiable to include detection of AFB in the case definition for definite tuberculosis because adenitis caused by nontuberculous mycobacteria is rare (typically only seen in nonBCG immunized children [17]) and we know that culture has relatively low sensitivity on lymph nodes, in particular on FNA $[18,19]$. Futhermore, in our cohort the culture positive cases were all of $\mathrm{m}$. tuberculosis with no other types of tuberculosis cultured. The problems defining case positivity especially in extra-pulmonary tuberculosis is a familiar challenge, in the Cochrane systematic review of Xpert for extra-pulmonary tuberculosis the specificity of Xpert on FNA was $86 \%$ when culture was the reference standard, but in the latent class meta-analysis model with a less stringent reference standard improved to $99 \%$, which is likely to be a much more accurate reflection of specificity [11]. Further impacting culture detection rates in our study is that we included participants on tuberculosis therapy; a sub-analysis

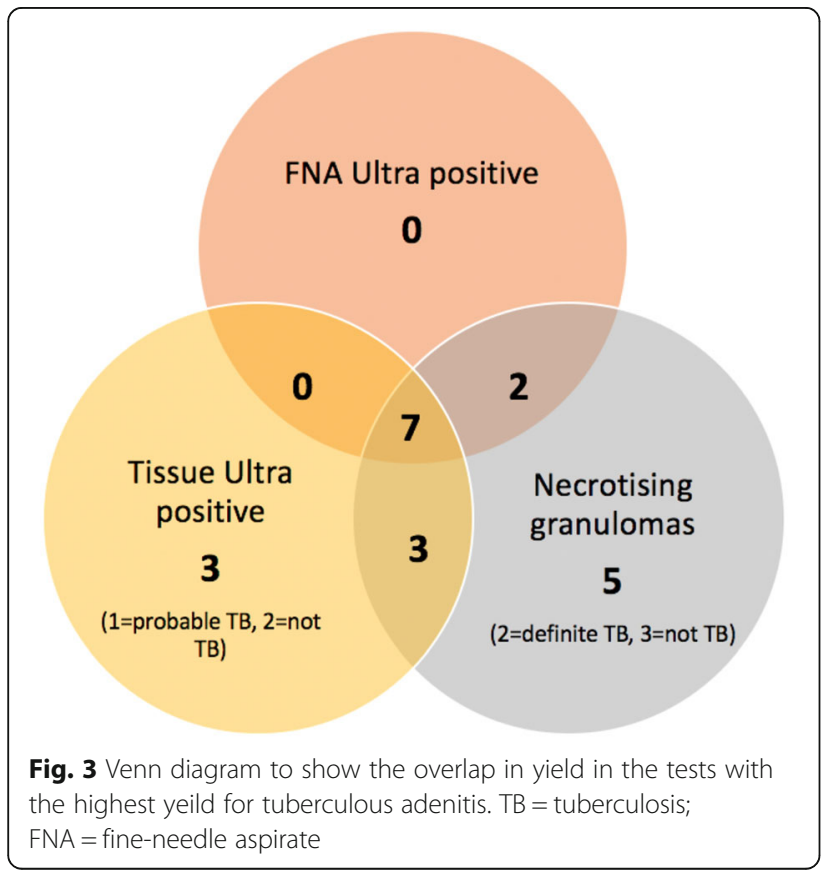

was performed excluding these participants (Table 3) where it did not appear to affect the results. Given the low yield for culture, our detection rates might have been higher if we sent both the aspirate and tissue for tuberculosis culture but due to financial constraints, we only sent one specimen for culture (either the aspirate or the tissue).

A major strength of our study is that is a prospective cohort study that tests the use of the Ultra in a 'real-world' clinic setting and can therefore address both diagnostic accuracy as well as clinical utility. We included participants in whom the final diagnosis of cervical swelling was not lymphadenopathy; this could be seen a limitation in that in these few situations the material tested was not lymph node tissue (e.g submandibular gland tissue) but there were no false positives in these patients and this answers an important clinical question about the risk of false positive results if tissue other than lymph node is biopsied. Other study strengths include the use of a standard protocol, and a single operator performing the FNA and core-needle biopsy.

\section{Conclusion}

The Ultra on FNA and on tissue had good sensitivity, and high specificity in our primary analysis. Ultra on FNA is a cheap and simple bedside procedure with a fast turnover time and is the most appropriate the initial diagnostic test where tuberculosis adenitis is suspected. AFBs on air-dried smear on FNA has low sensitivity and should be replaced by the Ultra. Core-needle biopsy with a repeat Ultra when granulomas are identified is an appropriate second investigation as it may confirm tuberculosis infection and importantly allows for histological examination and early diagnosis of lymphoma or other malignancies without the need for excision biopsy. 


\section{Abbreviations}

AFB: Acid-fast bacilli; ART: Antiretroviral therapy; Cl: Confidence Interval; ECOG: Eastern European Cooperative Group; EPTB: Extrapulmonary tuberculosis; FNA: Fine-Needle Aspiration; LAM: Lipoarabinomannan; OR: Odds Ratio; OS: Overall Survival; PLWH: People Living with HIV; Ultra: Xpert MTB/RIF Ultra assay; Xpert: Xpert MTB/Rif Assay

\section{Acknowledgements}

We would like to thank Judi Van Heerden and Hafsah Tootla for the processing of the Ultra and microbiological specimens respectively.

\section{Disclaimer}

The contents of this publication are solely the responsibility of the authors and do not represent the official views of the National Institutes of Health $(\mathrm{NIH})$.

\section{Authors' contributions}

KA, EV and GM designed the research study. KA and JO ran the clinic under the supervision of VJL, FM and EV. KA and FM performed the biopsies. KA, EV and GM wrote the paper. The Xpert Ultra was performed in the lab under the supervision of MN. All authors read, critically appraised and approved the final manuscript.

\section{Authors' information}

MN is currently working at the School of Biomedical Sciences, University of Western Australia, Perth, Australia but was based at the University of Cape Town during the study period.

\section{Funding}

This work was supported by U.S. National Institutes of Health, Fogarty International Center [grant number D43-TW010345 and grant number D43TW010543]; and the Peter Jacobs Bursary Trust. GM was supported in part by the National Research Foundation of South Africa [grant number 119078]. EV was supported in part by the Thuthuka grant (TTK14052268878). The funders had no role in the design of the study and collection, analysis, and interpretation of data and in writing the manuscript.

\section{Availability of data and materials}

The datasets used and/or analysed during the current study are available from the corresponding author on reasonable request.

\section{Ethics approval and consent to participate}

Ethics was approved by the University of Cape Town Human Research Ethics Committee (HREC), approval number 674/2017. Written informed consent was obtained from each participant.

\section{Consent for publication}

Not applicable.

\section{Competing interests}

The authors declare that they have no competing interests.

\section{Author details}

'Division of Haematology, Department of Medicine, University of Cape Town, Anzio Rd, Observatory, Cape Town 7925, South Africa. ${ }^{2}$ Department of Surgery, University of Cape Town, Cape Town, South Africa. ${ }^{3}$ Division of Medical Microbiology, University of Cape Town, Cape Town, South Africa. ${ }^{4}$ Division of Clinical Pharmacology, Department of Medicine, University of Cape Town, Cape Town, South Africa.

Received: 5 August 2019 Accepted: 28 December 2019

Published online: 13 January 2020

\section{References}

1. Sharma SK, Mohan A. Extrapulmonary tuberculosis. Indian J Med Res. 2004; 120:316-53.

2. Denkinger CM, Schumacher SG, Boehme CC, Dendukuri N, Pai M, Steingart KR. Xpert MTB/RIF assay for the diagnosis of extrapulmonary tuberculosis: a systematic review and meta-analysis. Eur Respir J. 2014;44:435-46.

3. Dorman SE, Schumacher SG, Alland D, et al. Xpert MTB/RIF Ultra for detection of Mycobacterium tuberculosis and rifampicin resistance: a prospective multicentre diagnostic accuracy study. Lancet Infect Dis. 2018; 18:76-84.

4. Xie $\mathrm{YL}$, Chakravorty S, Armstrong DT, et al. Evaluation of a rapid molecular drug-susceptibility test for tuberculosis. N Engl J Med. 2017;377:1043-54.

5. Bahr N, Nuwagira E, Evans E, et al. (2018). Diagnostic accuracy of Xpert MTB/ RIF Ultra for tuberculous meningitis in HIV-infected adults: a prospective cohort study. Lancet Infect Dis. 2018;18:68-75.

6. Bisognin F, Lombardi G, Lombardo D, Re MC, Dal MP. Improvement of Mycobacterium tuberculosis detection by Xpert MTB/RIF Ultra: a head-tohead comparison on Xpert-negative samples. PLoS One. 2018;13:e0201934.

7. Oken MM, Creech RH, Tormey DC, et al. Toxicity and response criteria of the eastern cooperative oncology group. Am J Clin Oncol. 1982;5:649-55.

8. Buderer NM. Statistical methodology: I. incorporating the prevalence of disease into the sample size calculation for sensitivity and specificity. Acad Emerg Med. 1996:3:895-900.

9. Wilson D, Nachega JB, Chaisson RE, Maartens G. Diagnostic yield of peripheral lymph node needle-core biopsies in HIV-infected adults with suspected smear-negative tuberculosis. Int J Tuberc Lung Dis. 2005;9:220-2.

10. Cohen JF, Korevaar DA, Altman DG, et al. STARD 2015 guidelines for reporting diagnostic accuracy studies: explanation and elaboration. BMJ Open. 2016;6:1-17.

11. Kohli M, Schiller I, Dendukuri N, et al. Xpert ${ }^{\circledR}$ MTB/RIF assay for extrapulmonary tuberculosis and rifampicin resistance. Cochrane Database Syst Rev. 2018;8:CD012768.

12. Bem C, Patil PS, Elliott AM, Namaambo KM, Bharucha H, Porter JD. The value of wide-needle aspiration in the diagnosis of tuberculous lymphadenitis in Africa. AIDS. 1993;7:1221-5.

13. Ellison E, Lapuerta P, Martin SE. Fine needle aspiration diagnosis of mycobacterial lymphadenitis. Sensitivity and predictive value in the United States. Acta Cytol. 1999;43:153-7.

14. Fain O, Lortholary O, Djouab $\mathrm{M}$, et al. Lymph node tuberculosis in the suburbs of Paris: 59 cases in adults not infected by the human immunodeficiency virus. Int J Tuberc Lung Dis. 1999;3:162-5.

15. Singh KK, Muralidhar M, Kumar A, et al. Comparison of in house polymerase chain reaction with conventional techniques for the detection of Mycobacterium tuberculosis DNA in granulomatous lymphadenopathy. J Clin Pathol. 2000:53:355-61.

16. Polesky A, Grove W, Bhatia G. Peripheral tuberculous lymphadenitis: epidemiology, diagnosis, treatment, and outcome. Medicine. 2005;84:350-62.

17. Asimacopoulos EP, Berry M, Garfield B, et al. The diagnostic efficacy of fineneedle aspiration using cytology and culture in tuberculous lymphadenitis. Int J Tuberc Lung Dis. 2010;14:93-8.

18. Fontanilla JM, Barnes A, Von Reyn CF. Current diagnosis and management of peripheral tuberculous lymphadenitis. Clin Infect Dis. 2011;53:555-62.

19. Wright CA, Hesseling AC, Bamford C, Burgess SM, Warren R, Marais BJ. Fineneedle aspiration biopsy: a first-line diagnostic procedure in paediatric tuberculosis suspects with peripheral lymphadenopathy? Int J Tuberc Lung Dis. 2009;13:1373-9.

\section{Publisher's Note}

Springer Nature remains neutral with regard to jurisdictional claims in published maps and institutional affiliations.

Ready to submit your research? Choose BMC and benefit from:

- fast, convenient online submission

- thorough peer review by experienced researchers in your field

- rapid publication on acceptance

- support for research data, including large and complex data types

- gold Open Access which fosters wider collaboration and increased citations

- maximum visibility for your research: over $100 \mathrm{M}$ website views per year

At $\mathrm{BMC}$, research is always in progress.

Learn more biomedcentral.com/submissions 